\title{
Assessment of Percutaneous Transluminal Coronary Angioplasty by Quantitative Coronary Angiography: Diameter Versus Densitometric Area Measurements
}

\author{
PATRICK W. SERRUYS; MD, JOHAN H. C. REIBER, PhD, WILLIAM WIJNS, MD, \\ MARCEL v.d. BRAND, MD, CORNELIS J. KOOIJMAN, MSc, HARALD J. ten KATEN, BSc, \\ and PAUL G. HUGENHOLTZ, MD
}

Cineangiograms of 138 patients who underwent percutaneous transluminal coronary angioplasty (PTCA) were analyzed with a computer-based coronary angiography analysis system. The results before and after dilatation are presented. In a first study group (120 patients), the severity of the obstructive lesions derived from the automatically detected contours was evaluated in absolute terms and in percent-diameter reduction. In a second group of patients, 18 coronary lesions were selected for their extreme severity and symmetric aspect before angioplasty as assessed from multiple views. In the second group, the densitometric percent-area stenosis was used to assess the changes in cross- sectional area after PTCA and was compared with the circular percent-area stenosis computed from the diameter measurements. Before PTCA, a good agreement exists between the densitometric percent-area stenosis and the circular percent-area stenosis. After PTCA, important discrepancies between these 2 types of measurements are observed. It is suggested that these discrepancies in results after PTCA can be accounted for by asymmetric morphologic changes in luminal cross section, which cannot be assessed accurately from diameter measurements in a single-plane view.

(Am J Cardiol 1984;54:482-488)
Previous studies of the hemodynamic effect of stenosis in an artery have shown that the most critical determinant of the severity is the minimal luminal crosssectional area. ${ }^{1}$ Assessment of the percent-area reduction in a stenotic area from the diameter measurements obtained from a single projection assumes a symmetric circular cross section, an assumption that is not always correct. 2,3 Even a technique of quantitating area stenosis from 2 orthogonal measurements and computing the area based on an elliptical model would fail to describe an asymmetric lesion accurately. ${ }^{4}$

However, if a relation between the thickness of the irradiated object and the density level in the angiographic image could be derived, the true luminal cross sections of a contrast-filled coronary artery could be computed, even from a single x-ray projection. ${ }^{5}$ From

From the Thoraxcenter, Erasmus University and University Hospital Dijkzigt, Rotterdam, the Netherlands. Manuscript received February 6, 1984; revised manuscript received May 14, 1984; accepted May 15, 1984.

Address for reprints: Patrick W. Serruys, MD, Catheterization Laboratory, Thoraxcenter, Erasmus University, P.O. Box 1738, 3000 DR Rotterdam, The Netherlands. these observations, it is clear that an objective and reproducible technique of quantitating percent changes in cross-sectional area stenosis is needed if one is to evaluate the efficacy of transluminal coronary angioplasty in a quantitative sense.

Cineangiograms of 138 patients who underwent percutaneous transluminal coronary angioplasty (PTCA) were analyzed with a computer-based coronary angiograph analysis system. The results from diameter and densitometric area measures before and after dilation are presented. ${ }^{6,7}$

\section{Methods}

Quantitative analysis of coronary obstructions: $C o n$ tour detection: The quantitative analysis of selected coronary segments was performed with the help of a computer-based coronary angiography analysis system; this system has been described extensively elsewhere. ${ }^{5-7}$

To analyze a selected $35-\mathrm{mm}$ cineframe, the film is placed on a specially constructed cine-video converter. This converter consists of a standard 35-mm Vanguard ${ }^{\circ}$ cinefilm transport mechanism, a drum with 6 different lens systems and a high-resolution video camera mounted on a motor-driven $x-y$ stage. ${ }^{5,8}$ By means of this cine-video converter, any portion 
of the $35-\mathrm{mm}$ cineframe can be selected with the appropriate magnification factor. Regions of interest in the image can be digitized and stored into the computer memory for subsequent processing. Operator interaction is possible with a writing table.

The computerized analysis of a selected coronary segment requires the manual definition of a number of center positions within the segment by means of the writing table. A smooth continuous curve, the centerline, is subsequently generated through these center positions. This centerline determines regions of interest of sizi $96 \times 96$ pixels, encompassing the arterial segments to be cligitized. Contour positions are detected along scanlines perpendicular to the local centerline directions on the basis of the first and second derivative values of the brightness information. ${ }^{7} \mathrm{~A}$ smoothing procedure is applied to each of the detected contours and all contour positions are corrected for pincushion distortion introduced by the image intensifier.

Calibration of the diarneter data is achieved by using the intracardiac catheter as a scaling device. To this end, the contours of part of the projected catheter are detected automatically in a way similer to that described for the arterial segment.

From the final contours, the diameter function is determined by computing the shortest distances between the left and right contour positions (the upper curves in Fig. 1). As a next step the computer a gorithm determines the position of the obstruction by searching for the minimal diameter value in the diameter function. The length of the selected obstruction site is determined from the diameter function on the basis of curvature analysis ano expressed in millimeters. The de tected boundaries of the obstruction are indicated in the diameter function with 2 dotted lines.

In arteries with a focal obstructive lesion and a clearly normal proximal or distal arterial segment, the choice of the reference region is straightforward and simple. However, in cases where the proximal or distal part of the arterial segment shows combinations of stenotic and ectatic areas, the choice may become difficult. To circumvent these problems, we implemented a method to express the severity of a coronary obstruction that does not depend on a user-defined reference region. This technique is denoted "interpolated percentdiameter stenosis measurement." Details have been reported elsewhere. 6 , The basic idea behind this technique is computer estimation of the original diameter values over the obstructive region (assuming there was no coronary disease present) based on the diameter function. On the basis of the proximal and distal centerline segments and the computed reference diameter function, the reference contours over the obstructive region can be reconstructed. The results of this technique applied to an aortocoronary bypass graft, successfully dilated and filmed in 2 orthogonal projections, are presented in Figure 1. The white areas in the figure are measures for the "atherosclerotic" plaque and are defined by the differences between the actual luminal contours and the reconstructed reference contours. The interpolated percent-diameter stenosis is then obtained by comparing the minimal diameter value at the obstruction with the corresponding value of the reference contour in this position (Fig. 1).

The accuracy of the quantification method has been validated with plexiglass phantoms filled with contrast medium (perspex models). ${ }^{7}$

Densitometric procedure: To determine the changes in cross-sectional areas of a coronary segment from the density information within the artery, the calibration of the brightneas levels in terms of the amount of $x$-ray absorption (LambertBeer's Law) is required.

The approach we have implemented corrects for spatially variant responses in the imaging chain and for the daily variations in the cinefilm processing. ${ }^{8}$ For the first part of the chain from the $x$-ray source to the output of the image intensifier, we assume Lambert-Beer's Law to be valid for the $x$-ray absorption and apply certain models for the $x$-ray source and the image intensifier. From the output of the image intensifier up to the brightness values in the digital image, the overall transfer function is measured on a pixel-by-pixel basis by means of 21 calibrated density frames, which are processed simultaneously with the rest of the coronary cinefilm.
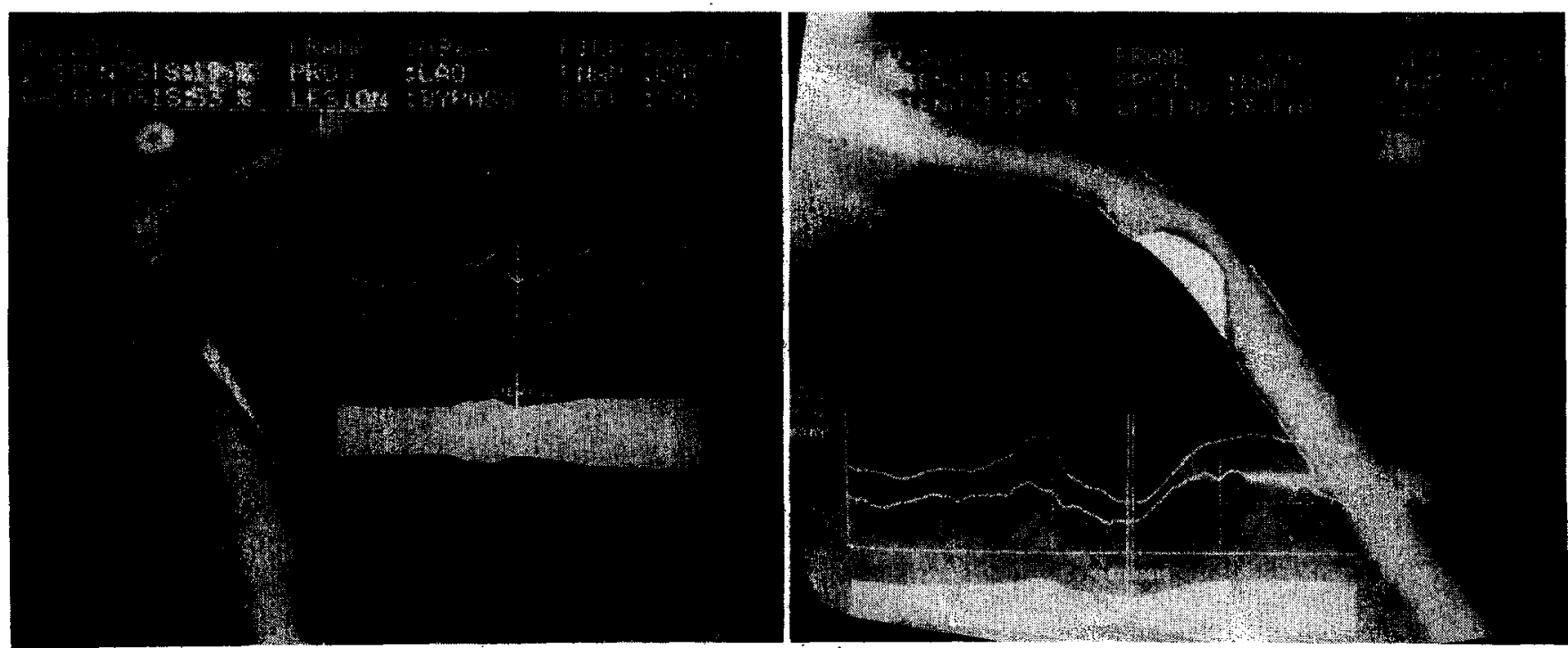

FIGURE 1. Contours and densitometric analysis of the severity of an obstruction in the same aortocoronary bypass graft, filmed in right (RAO) and left (LAO) anterior oblique projections. In each illustration, the dlagnostic diameter functlon (upper curve) and the densitometric area function (lower curve) are displayed on the video image. The white areas are a measure for the "atherosclerotic" plaque and are defined by the difference between the actual luminal contours, detected in by the computer and the reconstructed reference contours. The densitometric area stenosis (A-STENOSIS) measured in the orthogonal projections are 53 and $55 \%$, respectlvely, whereas the diameter stenosis (D-STENOSIS) based on detected contours are $19 \%$ in the LAO projection and $52 \%$ in the RAO projection. 
TABLE I Effect of Percutaneous Transluminal Coronary Angloplasty on 138 Obstructive Lestons in the First Study Group

\begin{tabular}{lccc}
\hline & Before PTCA & After PTCA & p Value \\
\hline $\begin{array}{l}\text { Reference } \\
\text { diameter }(\mathrm{mm})\end{array}$ & $3.40 \pm 0.68$ & $3.34 \pm 0.70$ & NS \\
$\begin{array}{l}\text { Obstruction } \\
\text { diameter }(\mathrm{mm})\end{array}$ & $1.28 \pm 0.40$ & $2.24 \pm 0.57$ & 0.001 \\
$\begin{array}{l}\text { Diameter } \\
\text { stenosis (\%) }\end{array}$ & $62 \pm 12$ & $34 \pm 15$ & 0.001 \\
\hline
\end{tabular}

NS = not significant; PTCA = percutaneous transiuminal coronary angloplasty.

To better understand the principles of the density measurements in the coronary artery the 2-dimensional brightness function of such a digitization matrix is displayed as a 3dimensional structure with the brightness level plotted along the $\mathrm{z}$-axis (Fig. 2B). The $\mathrm{x}$ and $\mathrm{y}$ axes of this structure correspond with the horizontal and vertical video scan directions (Fig. 2A). The coronary artery can be recognized as a mountain ridge, with a deep pass at the location of the obstruction. On every scanline a profile of brightness values is measured. This profile is transformed into an $\mathrm{x}$-ray absorption profile by means of the transfer function (Fig. 2C). The background contribution is estimated by an interpolative method and subtraction of this background yields the net cross-sectional absorption profile. Integration of this function results in a measure for the cross-sectional area at the particular scanline. By repeating this procedure for each scanline, the cross-sectional area function is obtained. The severity of the obstruction can now be expressed as a percent area reduction, by comparing the minimal area value at the obstruction with the reference value obtained following an interpolative approach, which is similar to the earlier described method for diameter measurements (Fig. 1).
The complete procedure has been evaluated with the cinefilms of perspex models of coronary obstructions. ${ }^{8}$

\section{Study Groups}

The first study group consisted of 120 patients who underwent a successful PTCA between September 1981 and December 1982; within 6 months after the procedure 50 of these patients agreed to undergo repeat cardiac catheterization.

The second study group consisted of 18 patients in whom the densitometric percent-area stenosis technique was used to assess the changes in percent cross-sectional area before and after PTCA. All data were obtained from single projections. The lesions were selected for their extreme severity and symmetric aspect before angioplasty as assessed from multiple views. PTCA was performed according to the technique of Grützig, using the equipment of Schneider (20- to 3.0- or 20to $3.7-\mathrm{mm}$ balloon), using a femoral route. In all cases, the pressure gradient across the obstructive lesion was recorded before and after dilatation. The inflation pressure ranged from 4 to $10 \mathrm{~atm}$ and the duration of the inflation was usually 30 to 60 seconds. Attempts at dilating the stenotic lesion were repeated as long as the gradient across the lesion persisted (4 to 10 times). Before the procedure all patients received aspirin and nifedipine; $\beta$-blocking drugs were not discontinued. During the procedure heparin and low-molecular-weight dextran were administered intravenously; direct intracoronary injection of nifedipine and isosorbide dinitrate was performed before the dilatation. To visualize the effect of the procedure, coronary angiography was performed immediately before and after transluminal angioplasty. Lateral, anteroposterior, oblique and hemiaxial views were usually obtained.

\section{Results}

In the first study group the quantitative analysis was limited to computation of the diameter values, derived
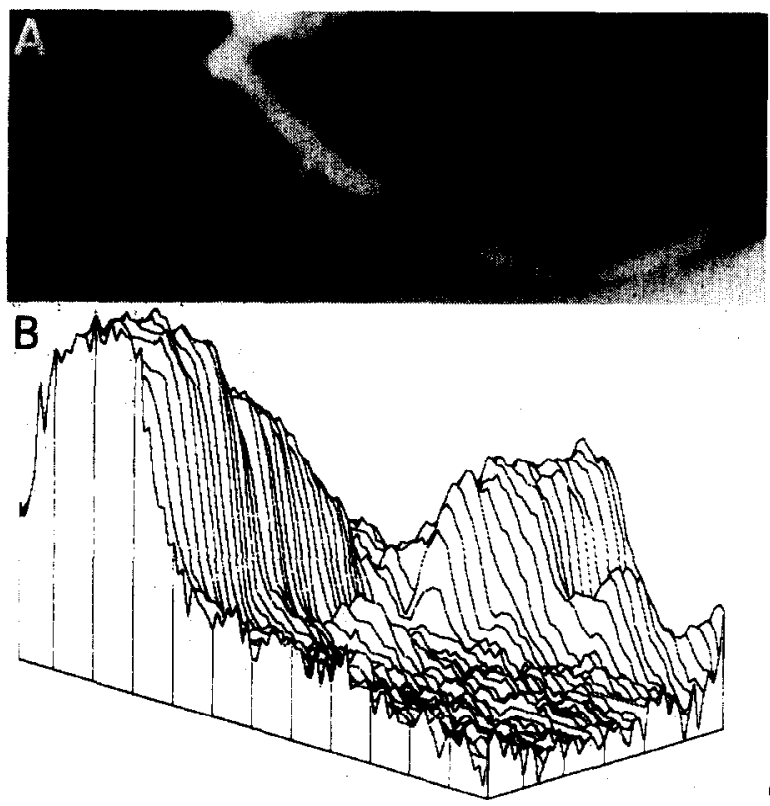

FIGURE 2. Basic aspects of the densitometric technique. A, a matrix is placed over the area selected for analysis from right coronary angiogram encompassing a severe coronary obstruction. B, pseudo 3-dimensional representation of the brightness information within the matrix. The coronary artery can be recognized as a mountain ridge with a deep pass at the site of the obstruction. C, this flow chart of the analysis indicates the main procechures followed for the computation of the densitometric area function. D, the brightness profile along 1 particular scanline is plotted. Positions with maximal values of the sum of first and second derivative functions left and right of the center positions of the artery correspond with the edge
positions of the artery.

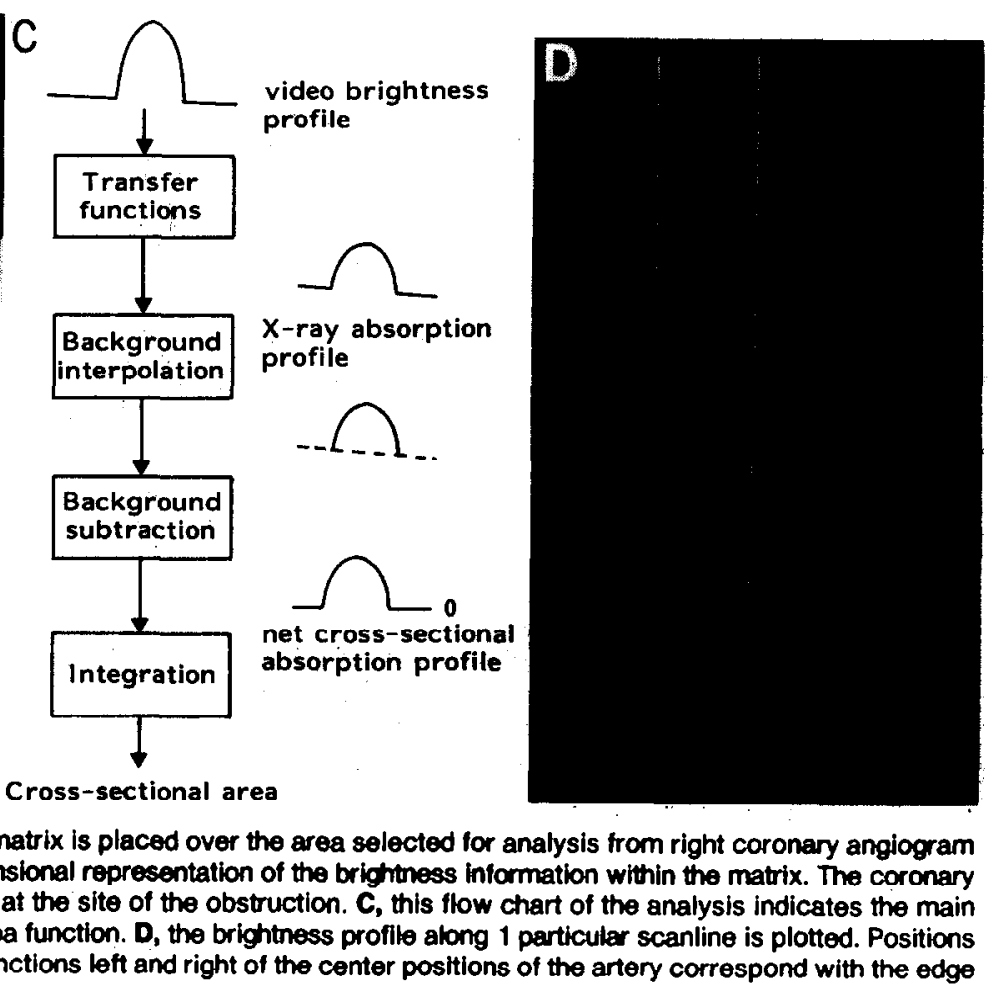


TABLE II Percent-Area Stenosis Derived from Detected Contours Versus Densitometric Area Measurement Before and After Angioplasty

\begin{tabular}{|c|c|c|c|c|c|c|}
\hline \multirow[b]{2}{*}{ Pt. No. } & \multicolumn{3}{|c|}{ Before PTCA } & \multicolumn{3}{|c|}{ After PTCA } \\
\hline & $\begin{array}{c}\% \text { Circular } \\
\text { A Sten }\end{array}$ & $\begin{array}{c}\% \text { Densitometric } \\
\text { A Sten }\end{array}$ & Difference & $\begin{array}{c}\% \text { Circular } \\
\text { A Sten }\end{array}$ & $\begin{array}{c}\% \text { Densitometric } \\
\text { A Sten }\end{array}$ & Difference \\
\hline $\begin{array}{c}1 \\
2 \\
3 \\
4 \\
5 \\
6 \\
7 \\
8 \\
9 \\
10 \\
11 \\
12 \\
13 \\
14 \\
15 \\
16 \\
17 \\
18 \\
\text { Moan } \\
\text { Corr Cooff: }\end{array}$ & $\begin{array}{l}69 \\
93 \\
94 \\
73 \\
85 \\
88 \\
85 \\
70 \\
85 \\
93 \\
57 \\
96 \\
95 \\
84 \\
89 \\
84 \\
88 \\
90 \\
84 \%\end{array}$ & $\begin{array}{l}69 \\
93 \\
97 \\
85 \\
89 \\
92 \\
90 \\
71 \\
90 \\
93 \\
61 \\
99 \\
94 \\
82 \\
93 \\
89 \\
94 \\
77 \\
87 \%\end{array}$ & $\begin{array}{c}0 \\
0 \\
4 \\
12 \\
4 \\
4 \\
5 \\
1 \\
5 \\
0 \\
4 \\
3 \\
-1 \\
-2 \\
4 \\
5 \\
6 \\
-13 \\
2.3 \% \\
\text { SD } 5 \%\end{array}$ & $\begin{array}{l}24 \\
57 \\
33 \\
36 \\
73 \\
42 \\
19 \\
21 \\
52 \\
23 \\
54 \\
46 \\
83 \\
60 \\
66 \\
51 \\
28 \\
44 \\
45 \%\end{array}$ & $\begin{array}{l}9 \\
71 \\
44 \\
64 \\
75 \\
47 \\
44 \\
36 \\
35 \\
47 \\
58 \\
17 \\
82 \\
46 \\
71 \\
66 \\
36 \\
10 \\
48 \%\end{array}$ & $\begin{array}{r}-15 \\
14 \\
11 \\
28 \\
2 \\
5 \\
25 \\
15 \\
-17 \\
24 \\
4 \\
-29 \\
-1 \\
-14 \\
5 \\
15 \\
12 \\
-34 \\
2.8 \% \\
\text { so } 18 \%\end{array}$ \\
\hline
\end{tabular}

A Sten = area stenosis; Corr Coeff = correlation coefficient; PTCA = percutaneous transluminal coronary angioplasty; SD = standard deviation.

from the detected contours. The severity of the obstructive lesion was expressed in relative percent narrowing and in absolutis values in millimeters. For statistical analysis the average value of the measurements obtained in multiple angiographic projections (2 to 6 views) were determined for each person. The results for the 138 lesions of the first study group are summarized in Table I. On the average, the reference diameter remains unchanged after PTCA; the obstruction diameter increases from $1.28 \pm 0.40 \mathrm{~mm}$ to $2.24 \pm 0.57 \mathrm{~mm}$ (p $<0.001)$; the interpolated diameter stenosis is thus reduced from $62 \pm 12 \%$ to $34 \pm 15 \%$ ( $p<0.001$ ).
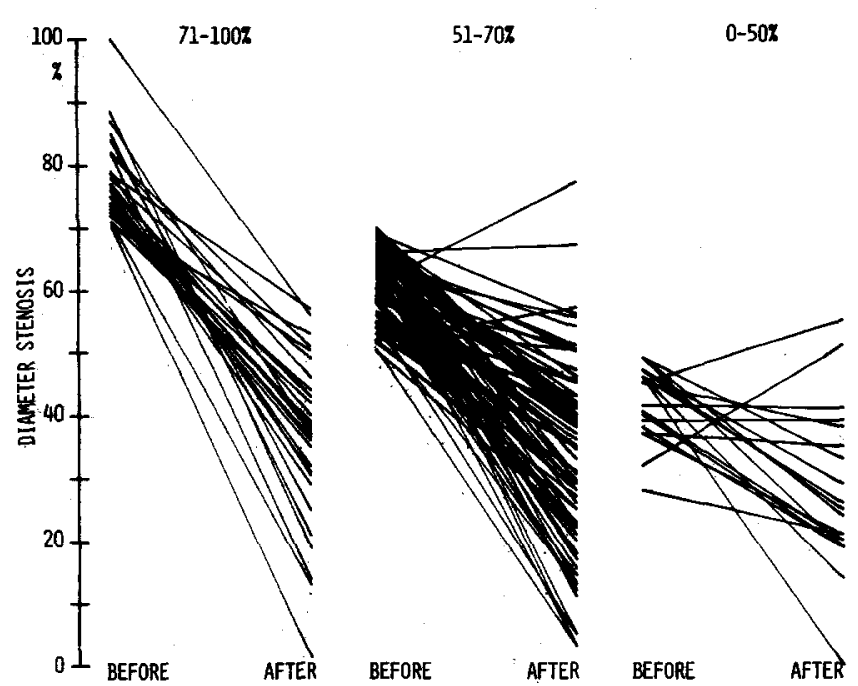

FIGURE 3. Individual data of change in percent-diameter stenosis for 3 subsets of coronary stenosiss according to the initial severity. In the group with a stenosis of $70 \%$, the diameter stenosis decreased on the average from $76 \pm 7 \%$ to $33 \pm 15 \%$. In the intermediate group (51 to $70 \%$ ). the diameter stenosis decreased from $63 \pm 6 \%$ to $33 \pm$ $15 \%$, and in the last group ( 0 to $50 \%$ ), it decreased from $42 \pm 6 \%$ to $25 \pm 16 \%$.
Three groups of individual data are shown in Figure 3 according to the severity of the interpolated percent diameter stenosis before PTCA. Before PTCA. 26\% of the lesions had a percent-diameter stenosis of 71 to $100 \%$, whereas $58 \%$ of the lesions ranged from 51 to $70 \%$. In the remaining $16 \%$ of the lesions that were dilated, the percent-diameter stenosis was less than $51 \%$. In 4 of these patients, PTCA was performed immediately after intracoronary fibrinolysis ${ }^{9}$; in 18 other instances, we felt justified in dilating a second, less critical lesion during the same session.

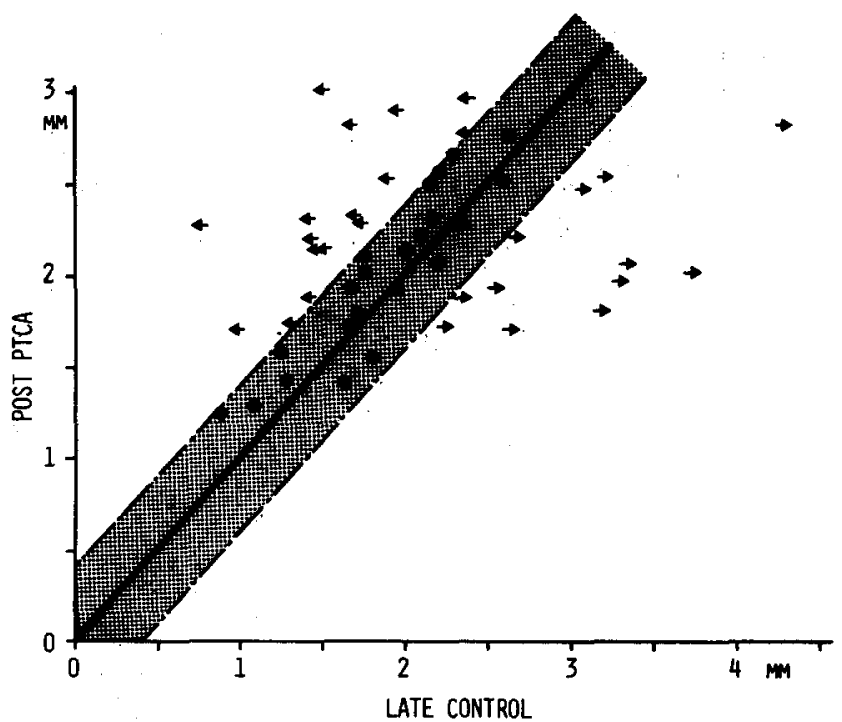

FICURE 4. Quantitative angiographic follow-up after 6 months (late control) of the minimal obstruction diameter in $\mathbf{5 0}$ successfully dlated lesions with comparison to the same parameter immediately after the dilatation. The sheded erea represents the total measurement variability ( \pm 2 standard devlations) of repeated coronary cineanglography and quantitative anatysis symbois: $\leftarrow=$ late deterioration of the initial angiographic results; $O$ unchanged minimal obstruction diameter; $\rightarrow$ = late improvement. 

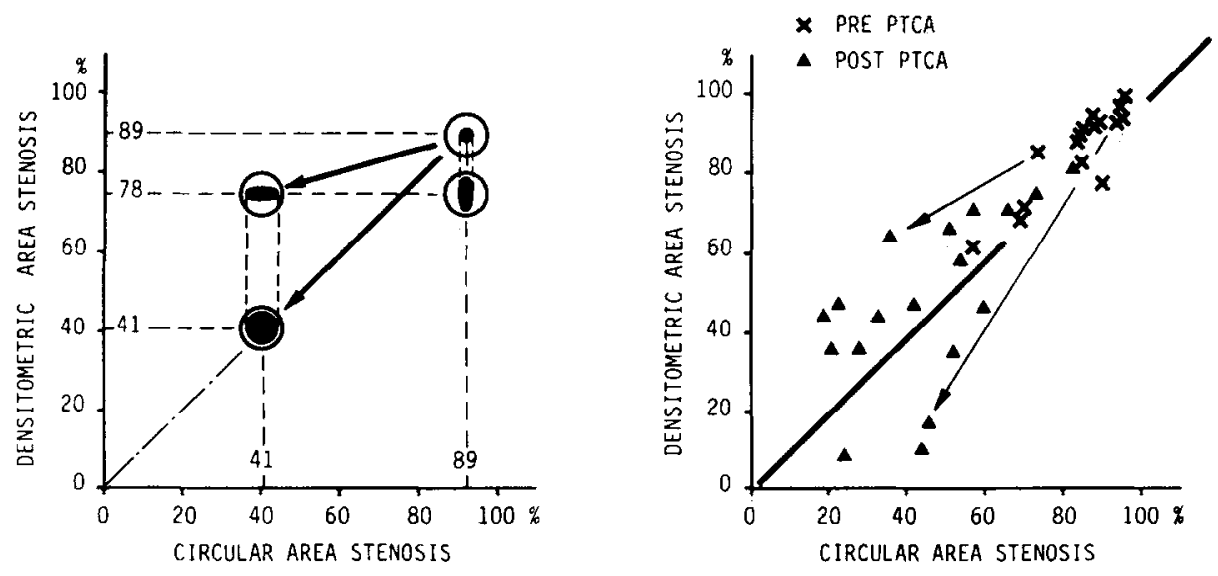

FIGURE 5. Left, schematic representation of the potential asymmetric morphologic changes in luminal cross section during angioplasty. Let us assume before percutaneous transluminal coronary angioplasty (PTCA) a circular cross section (area stenosis: $89 \%$ ) at the site of the stenosis. After angioplasty, 3 hypothetical situations are observed: (1) an elliptical cross section with the long axis perpendicular to the image intensifier; (2) an elliptical cross section with the long axis parallel to the image intensifier; and (3) an enlarged cross section. For the 2 asymmetric dilatations, the percent-area stenosis ( 41 and $89 \%$ ) derived from diameter measurement assuming a circular cross-sectional model differs from the densitometric percent area stenusis $(78 \%)$. Right, before and after (PRE and POST) PTCA comparison between densitometric area stenosis and area stenosis derived from the diameter measurements.
The quantitative angiographic follow-up of the minimal obstruction diameters in 50 successfully dilated lesions is shown in Figure 4.

A change superior to the total measurement variability of repeated coronary cineangiography and quantitative analysis $(0.44 \mathrm{~mm}$ for obstruction diameter, i.e., 2 standard deviations (SD) of difference of duplicate measurements) ${ }^{10}$ was considered as significant.

In 22 of these lesions, the residual obstruction diameter, measured immediately after PTCA, remained unchanged over a period of 6 months. In 16 other patients, some degree of restenosis occurred and in 12, late further improvement was observed.

In the second group, the densitometric percent-area stenosis was used to assess the changes in cross-sectional area after PTCA and compared with the circular per-

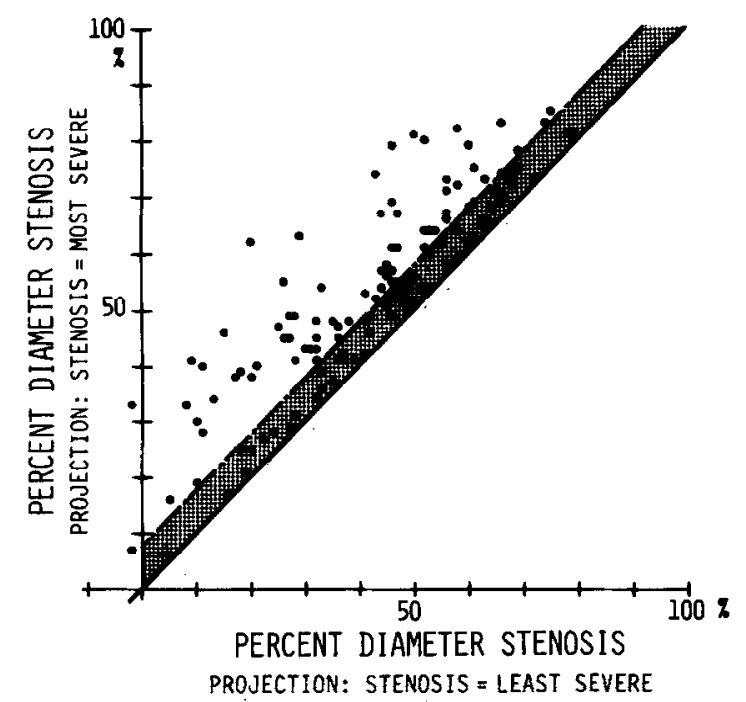

FIGURE 6. Asymmetry of 120 obstructive lesions analyzed in more than 1 projection. Horizontal axis, percent-diameter stenosis measured in the less severe angiographic projection; vertical axis, percent-diameter stenosis of the same lesion measured in the most severe projection. cent-area stenosis computed from the diameter measurements. The comparative data are shown in Table II and Figure 5. Before PTCA, a good agreement existed between the densitometric percent-area stenosis and the circular percent-area stenosis (SD of the difference $=5.0 \%$ area stenosis). After PTCA, important discrepancies between these 2 types of measurements were observed (SD of the difference $=18 \%$-area stenosis). It is suggested that these discrepancies in results after PTCA can be accounted for by asymmetric morphologic changes in luminal cross section, which cannot be assessed accurately from diameter measurements in a single-plane view.

\section{Discussion}

Whenever a lesion appears to be of different severity when viewed from multiple projections, asymmetry should be suspected. In this study, asymmetry is considered present when the percent-diameter stenosis measured in 1 angiographic view exceeded that measured in another view by more than 2 SDs of the method used. As previously shown, ${ }^{10,11}$ the total measurement variability of repeated coronary cineangiography and

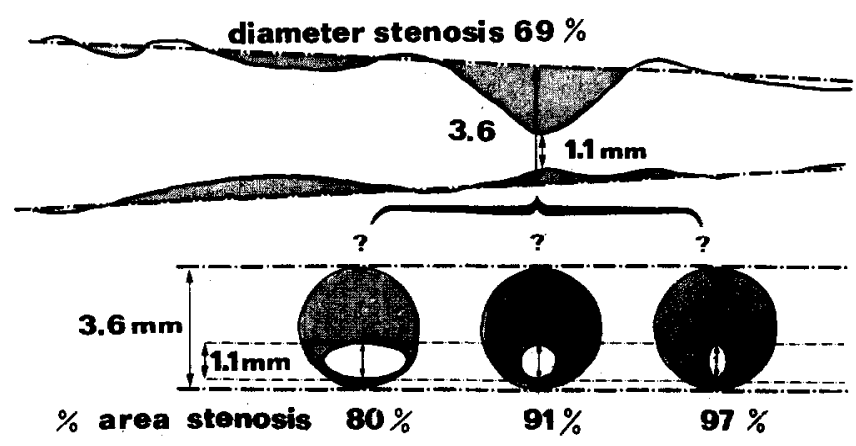

FIGURE 7. Schematic representation of a coronary obstruction with an interpolated diameter stenosis of $69 \%$ measured in a single projection. The percent-area stenosis, computed from diameter measurements, varied between 80 and $97 \%$ depending on the circular or elliptical model applied for the computation. 


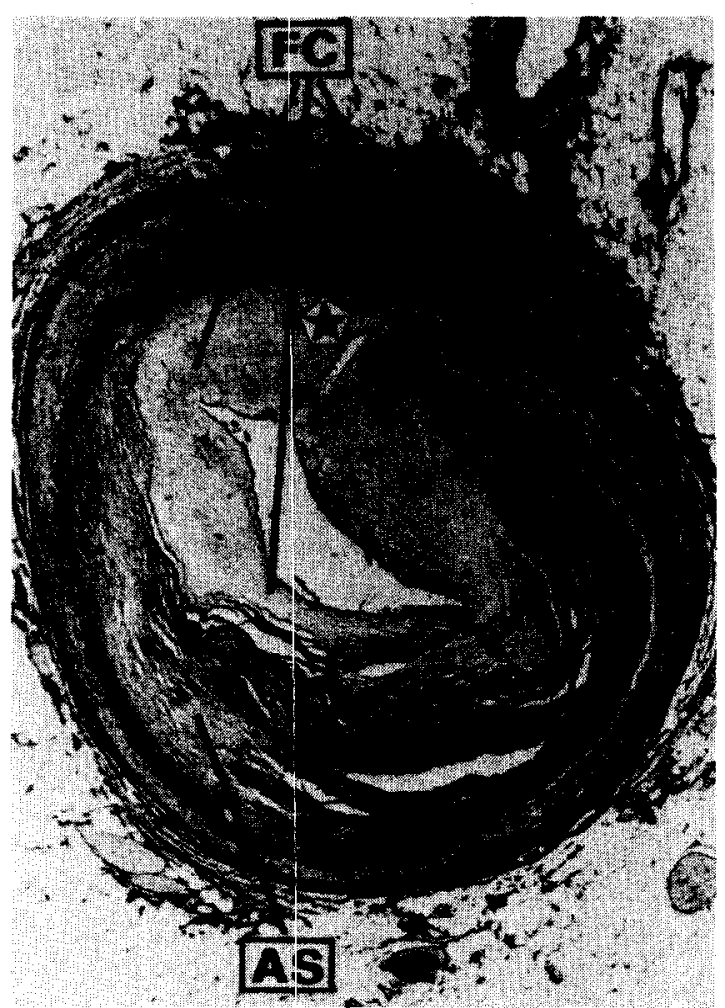

FIGURE 8. Histologic section through a stenotic lesion successfully dilated 5 months before the death of the patient. A disruption of the medial layer (star) is present, which had led to medial dissection. The false channel and the major piart of the lumen are filled with fibrocellular tissue (FC). The preexistent atherosclerotic plaque (AS) is readily identified.

quantitative analysis was $7.8 \%$ of diameter stenosis. In a previously reported study, ${ }^{11}$ when 120 lesions were analyzed in several orthogonal projections, asymmetric lesions were seen in more than half of the patients (Fig. 6). This shows that an atheromatous lesion may not always involve the entire circumference of the vessel but frequently results in an asymmetric or eccentric lesion. From postmortem data, ${ }^{12}$ it has been proved that a diseased vessel often looks like an exaggerated ellipse in which, ultimately, a slit-like lumen with a crescent shape represents the "artery." It has been argued that this latter aspect is a product of postmortem arterial fixation with sectioning; in the unpressurized state, 13,14 yet the present data indicate that this is not an artifact. The corollary of these considerations is that the severity of the lesion to be dilated should be quantitated in as many angiographic projections as possible when its efficacy is to be assessed by diameter measurements.

For the entire group the mean-diameter stenosis before PTCA was $62 \%$, as an average of multiple views. For the subset of lesions exceeding $50 \%$, it was $69 \%$. This value is almost $10 \%$ lower than that commonly reported when values are based on subjective reading of angiograms. ${ }^{15-17}$ Such visual interpretation of diameter reductions is subject to systematic overestimation of the severity of the stenosis, as shown by several investigators. ${ }^{18,19}$ Luminal reductions greater than $90 \%$ with minimal obstruction diameter of $0.35 \mathrm{~mm}$ are unlikely to be crossed smoothly even by a low-profile deflated balloon catheter, which has a mean diameter of $0.8 \mathrm{~mm}$. A value of $80 \%$ of mean-diameter stenosis commonly reported before PTCA corresponds to a $96 \%$ reduction of the luminal area. Again, this is unlikely to occur in patients with chronic stable angina because this would have limited the coronary blood flow at rest to a minimum. In fact, such restrictions are incompatible with adequate blood supply unless collateral channels are present. ${ }^{20} \mathrm{~A}$ diameter stenosis of $69 \%$ measured in a single projection could be consistent with a cross-sectional area stenosis between 80 and $97 \%$, depending on whether a circular or an elliptical model is applied (Fig. 7).

The results of cross-sectional area measurements obtained in the second study group suggest the creation of asymmetric lesions after angioplasty. As demonstrated elegantly by Block et $\mathrm{al}^{21}$ in rabbit arteries after experimentally induced atherosclerotic lesions, transluminal angioplasty leads to the breaking of the intimal surface of the atherosclerotic lesion. This split may extend to the internal elastic membrane. Angiography performed after such procedures in the rabbit frequently shows an irregular column of contrast in this area. As suggested by the investigators, these irregularities must certainly represent contrast material within the remains of the atherosclerotic plaque. Recently, human coronary arteries that had undergone angioplasty were analyzed. They have shown changes identical to those seen in animal models. ${ }^{22-24}$ Such a disruption of the medial layer creating a slit-like appendix to the original lumen is shown in Figure 8. Because this tear in the wall is filled by fibrocellular tissue, it must be inferred that the asymmetric morphologic aspect is not a postmortem artifact.

In conclusion, our angiographic study suggests that changes in the luminal area of an artery produced by the mechanical disruption of its internal wall cannot be assessed accurately from the detected contour of the vessel from a single-plane angiographic view. Therefore, the diagnostic value of this type of measurement is restricted by the fact that the angioplastic changes are eccentric in nature. To obviate this limitation, the use of densitometry to compute cross-sectional areas from single views is advocated.

\section{References}

1. Mates RE, Gupla RL, Bell AC, Klocke FJ. Fluid dynamics of coronary artery stenosis. Circ Res 1978;42:152-162.

2. Roberts WC. The coronary arteries and left ventricle in clinically isolated angina pectoris. Circulation 1976;54:388-390.

3. Freudenberg H, Lichtlen P. Postmortale Koronarangiographie. In: Lichtlen PR, ed. Koronarangiographie. Erlangen: Verlag Dr Med D. Straube; 1979: 341-351.

4. Brown BG, Bolson EL, Dodge HT. Arteriographic assessment of coronary atherosclerosis. Review of current methods, their limitations and clinical atherosclerosis. Review of current methods,

5. Relber JHC, Gerbrands JJ, Kooljman CJ, Schuurblers JCH, Slager CJ, den Boer A, Semrys PW. Quantitative coronary angiography with automated contour detection and densitometry; technical aspects. In: Just $H$, Heintzen $\mathrm{PH}$, eds. Angiocardiography, Current Status and Future Developments. Heidelberg: Springer-Verlag, 1984, in press.

6. Relber JHC, Gerbrands JJ, Booman F, Troost CJ, den Boer A, Slager CJ, Schuurbiers JCH. Objective characterization of coronary obstructions from monoplane cineangiograms and three-dimensional reconstruction of an monoplane cineanglograms and three-dimensional reconstuction of an tion of Computers in Medicine. IEEE catalog no. Th 0095-0;1982:93100.

7. Kooilman CJ, Reiber JHC, Gerbrands JJ, Schuurblers JCH, Slager CJ, den boer A, Serruys PW. Computer-aided quantitation of the severity of coronary obstructions from single view cineangiograms. International 
Symposium on Medical Imaging and Image Interpretation. IEEE catalog no. 82CH1804-4, 1982:59-64.

8. Reiber JHC, Slager CJ, Schuurbiers JCH, den Boer A, Gerbrands JJ, Troost GJ, Scholts B, Kooljman CJ, Serruys PW. Transfer functions of the $x$ ray cine video chain applied to digital processing of coronary cineangiograms. In: Heintzen PH, Brennecke R, eds. Digital Imaging in cardiovascular radiIn: Heintzen PH, Brennecke R, eds. Digital lmaging in cardiovascular
ology. Stuttgart-New York: George Thieme Verlag; 1983:89-104.

9. Serruys PW, Wijns W, Van den Brand M, Ribeiro V, FiorettI P, Simoons ML, Kooljman CJ, Relber JHC, Hugenholtz PG. Is transluminal coronary angioplasty mandatory after successful thrombolysis? Quantitative coronary angiographic study. Br Heart J 1983;50:257-265

10. Serruys PW, Hooghoudi EH, Reiber JHC, Slager C, Brower RW, Hugenholtz PG. Influence of intracoronary nifedipine on left ventricular function coronary vasomotility, and myocardial oxygen consumption. Br Heart J 1983;49:427-441

11. Wlins W, Serruys PW, Van den Brand M, Suryapranata $H$, Kooljman CJ, Reiber JHC, Hugenholiz PG. Progression to complete coronary obstruction Reiber JHC, Hugenholtz PG. Progression to complete coronary obstruction without myocardial infarction in patients who are candidates for percuta neous transluminal angioplasty: a 90 day angiographic follow-up in prognosis of coronary heart disease. In: Roskamm H, ed. Progression of Coronary Arteriosclerosis. New York: Springer-Verlag, 1983:190-195.

12. Roberts WC, Buja LM. The frequency and significance of coronary arterial thrombi and other observations in fatal acute myocardial infarction. Am J Med 1972;52:425-433.

13. Arnett EN, Isner JM, Redwood DR, Kent KM, Baker WP, Ackerstein H, Poberts WC. Coronary artery narrowing in coronary heart disease: comparison of cineangiographic and necropsy findings. Ann Intern Med 1979;91:350-356

14. Brown BG, Bolson E, Frimer M, Dodge HT. Computer-assisted measurements of coronary artery stenosis [letter]. Circulation 1979;60:1196.

15. Cowley MW, Velrovec GW, Wollgang TC. Efficacy of percutaneous transluminal coronary angioplasty: technique, patient selection, salutary results, limitations and complications. Am Heart J 1981;101:272-280.

16. Meier B, Gruentzlg AR, Goebel N, Pyle R, von Gosslar W, Schlumpl M. Assessment of stenoses in coronary angioplasty. Inter-and intraobserver variability. Int J Cardiol 1983;3:159-169.

17. Kent KM, Bentivoglio LG, Block PC. Cowley MJ, Dorros J, Gosselin AJ, Gruntzlg A, Myler RK, Simpson J, Stertzer HS, Williams 'DO, Fisher L, Grunizlg A, Mylor RK, Simpso Gillesple MJ, Detre K, Kelsey S, Mullin SM, Mock MB. Percutaneous transluminal coronary angioplasty: report from the registers of the National Heart, Lung, and Blood Institute. Am J Cardiol 1982;49:2011-2020.

18. Cherrier F, Booman F, Serruys PW, Cullilere M, Danchin N, Reiber JHC. L'angiographie coronaire quantitative. Application à l'évaluation des angioplasties transluminales coronaires. Arch Mal Coeur 1981;74:13771387.

19. Gerbrands JJ, Reiber JHC, Booman F. Computer processing and classification of coronary occlusions. In: Gelsema ES, Kanal LN, eds. Pattern fication of coronary occlusions. In: Gelsema ES, Kanal LN,

20. McMahon MM, Brown BG, Culingnan R, Rolett EL, Bolson E, Frimer M, Dodge HT. Quantitative coronary angiography: measurement of the critical stenosis in patients with unstable angina and single-vessel disease without collaterals. Circulation 1979;60:106-113.

21. Block PC, Baughman KL, Pasternale RC, Fallon JT. Transluminal angioplasty: correlation of morphologic and angiographic findings in an experimental model. Circulation 1980;61:778-785.

22. Holmes DR, Vlietstra RE, Mock MB, Reeder GS, Smith HC, Bove AA, Bresnakan JF, PIchler JM, Schaff HV, Orszulak TA. Angiographic changes produced by percutaneous transluminal coronary angloplasty. Am J Cardiol produced by percutan

23. Block PC, Myler RK, Stertzer S, Fallon JT. Morphology after transluminal angioplasty in human beings. N Engl J Med 1981;305:382-385.

24. Essed CE, Van den Brand M, Becker AE. Transluminal coronary angioplasty and early restenosis. Fibrocellular occlusion after wall laceration. $\mathrm{Br}$ Heart J 1983;49:393-396. 